\title{
CMM Technology
}

Federal Manufacturing \& Technologies

Robert C. Ward

KCP-613-8518

Published October 2008

Final Report on 706685

Approved for public release; distribution is unlimited.

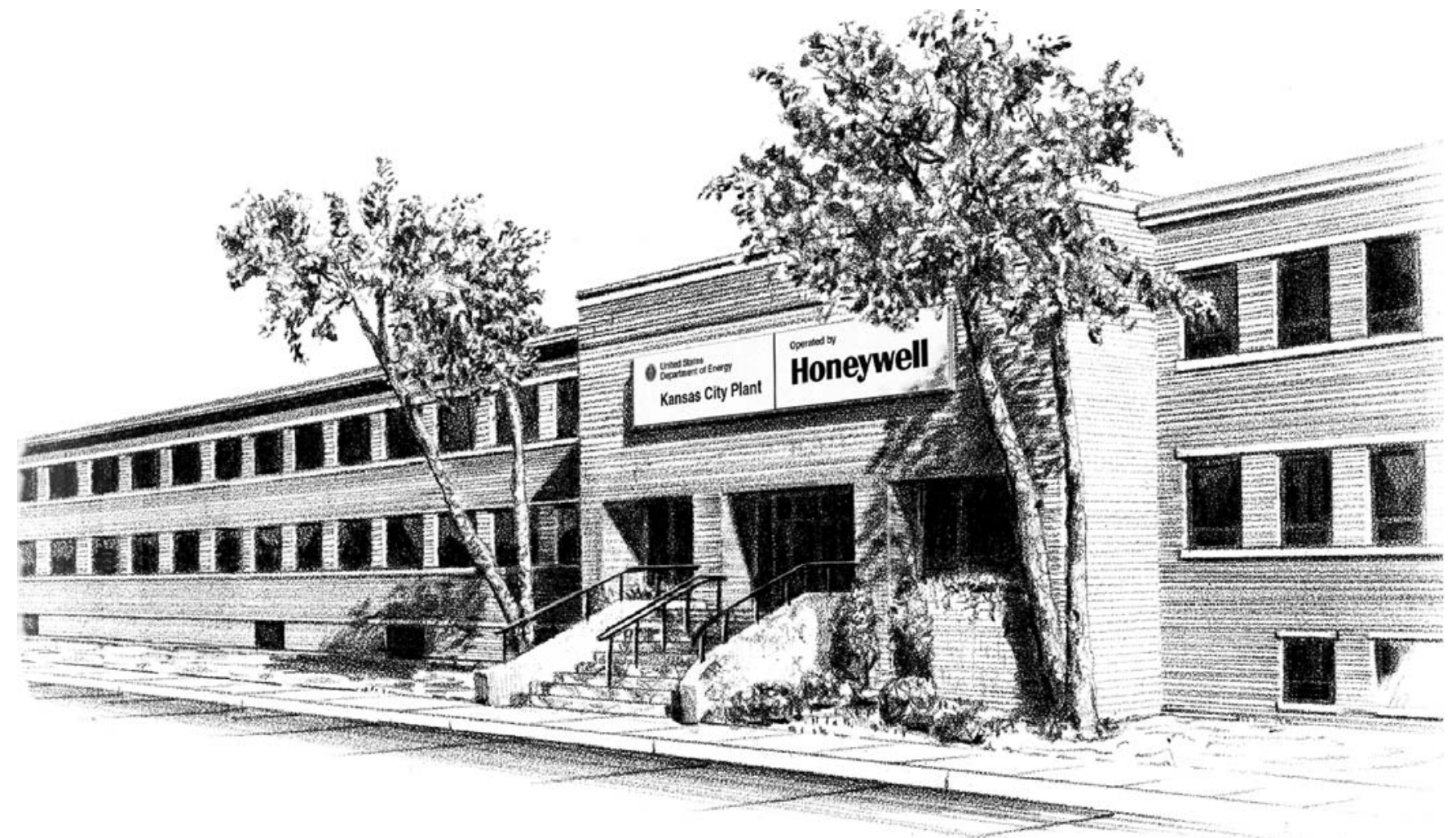

Prepared under prime contract DE-ACO4-01AL66850 for the

United States Department of Energy 


\section{DISCLAIMER}

This report was prepared as an account of work sponsored by an agency of the United States Government. Neither the United States Government nor any agency thereof, nor any of their employees, makes any warranty, express or implied, or assumes any legal liability or responsibility for the accuracy, completeness, or usefulness of any information, apparatus, product, or process disclosed, or represents that its use would not infringe privately owned rights. Reference herein to any specific commercial product, process or service by trade names, trademark, manufacturer, or otherwise, does not necessarily constitute or imply its endorsement, recommendation or favoring by the United States Government or any agency thereof. The views and opinions of authors expressed herein do not necessarily state or reflect those of the United States Government or any agency thereof.

All data prepared, analyzed and presented has been developed in a specific context of work and was prepared for internal evaluation and use pursuant to that work authorized under the reference contract. Reference herein to any specific commercial product, process or service by trade name, trademark, manufacturer, or otherwise, does not necessarily constitute or imply its endorsement, recommendation or favoring by the United States Government, any agency thereof or Honeywell Federal Manufacturing \& Technologies, LLC.

Printed in the United States of America.

This report has been reproduced from the best available copy.

Available to DOE and DOE contractors from the Office of Scientific and Technical Information, P.O. Box 62, Oak Ridge, Tennessee 37831; prices available from (865) 576-8401, FTS 626-8401.

Available to the public from the National Technical Information Service, U.S. Department of Commerce, 5285 Port Royal, Rd., Springfield, Virginia 22161, (703) 487-4650.

A prime contractor with the United States Department of Energy under prime contract DE-ACO4-01AL66850.
Honeywell Federal Manufacturing \& Technologies P. O. Box 419159 Kansas City, Missouri, 64141-6159 


\section{Honeywell}

\section{KCP-613-8518 \\ Distribution Category UC-42}

Approved for public release; distribution is unlimited.

\section{CMM TECHNOLOGY}

Robert C. Ward

KCP-613-8518

Published October 2008

Final Report on 706685

Project Team:

Robert C. Ward

Gary D. Akers

Steven L. Brooks

Curtis W. Brown

Noel C. Christensen 


\section{Contents}

Section Page

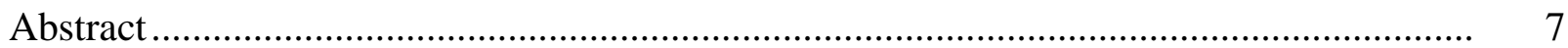

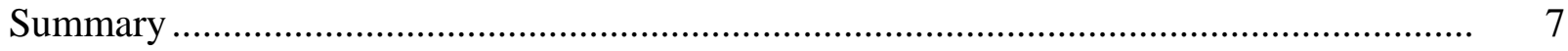

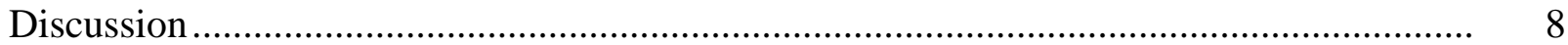

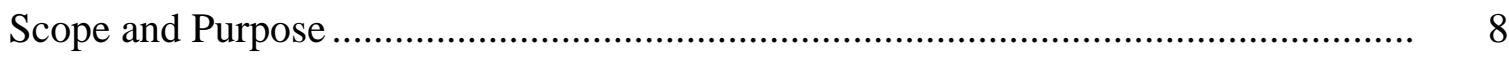

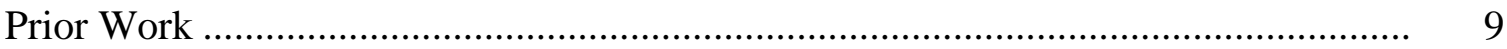

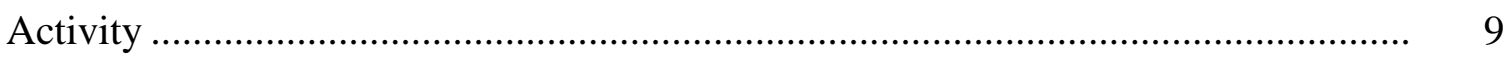

CMM Data Analysis ................................................................................ 9

CMM Hardware and Software Improvements......................................... 18

Reverse Engineering Software Evaluation ............................................. 20

Dimensional Metrology Standards ............................................................ 22

Model-Based Enterprise.......................................................................... 23

Precision Measurement Database .................................................................. 25

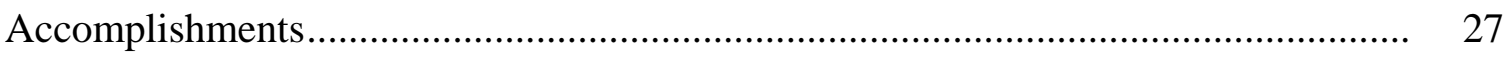

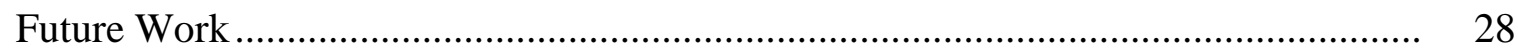




\section{Illustrations}

Figure Page

Figure 1: CMM Data Transfer Process ...................................................................... 10

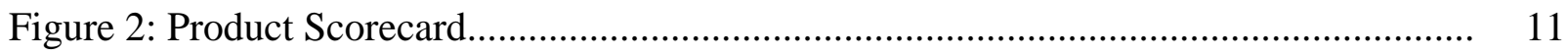

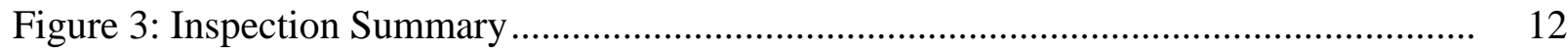

Figure 4: Zeiss UMESS Data File ....................................................................... 13

Figure 5: Zeiss UMESS-LX Data File .....................................................................

Figure 6: Apollo MeasureMax Data File ................................................................. 15

Figure 7: Apollo Metrologic Data File .................................................................. 16

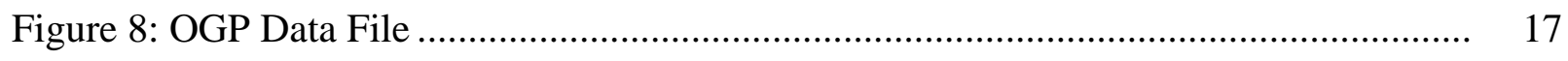

Figure 9: Zeiss Calypso Software ..................................................................... 18

Figure 10: Zeiss Calypso Planner Software ............................................................ 19

Figure 11: Zeiss Calypso Simulation Software ................................................... 20

Figure 12: Raindrop Geomagic Studio Reverse Engineering Software .......................... 21

Figure 13: Dimensional Measuring Interface Standard (DMIS) .................................... 22

Figure 14: Feature-Based Tolerancing (FBTol) …................................................. 23

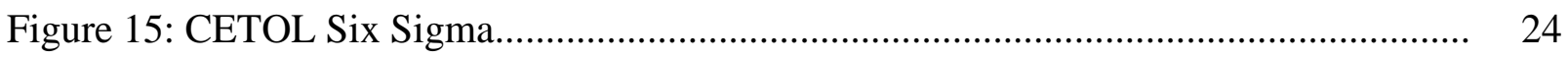

Figure 16: Job Management System: Main Menu..................................................... 25

Figure 17: Job Management System: Cycle Time Table ................................................ 26

Figure 18: Inspection Job Management System: Cycle Time Chart ............................... 26

Figure 19: Inspection Job Management System: Estimated Vs. Actual Time ................... 27 


\begin{abstract}
This project addressed coordinate measuring machine (CMM) technology and model-based engineering. CMM data analysis and delivery were enhanced through the addition of several machine types to the inspection summary program. CMM hardware and software improvements were made with the purchases of calibration and setup equipment and new model-based software for the creation of inspection programs. Kansas City Plant (KCP) personnel contributed to and influenced the development of dimensional metrology standards. Model-based engineering capabilities were expanded through the development of software for the tolerance analysis of piece parts and for the creation of model-based CMM inspection programs and inspection plans and through the purchase of off-the-shelf software for the tolerance analysis of mechanical assemblies. An obsolete database application used to track jobs in Precision Measurement was replaced by a web-based application with improved query and reporting capabilities. A potential project to address the transformation of the dimensional metrology enterprise at the Kansas City Plant was identified.
\end{abstract}

\title{
Summary
}

This project included several different activities, each of which addressed a technical gap in the areas of CMM technology and model-based technology.

In the area of inspection data analysis, a program was developed to summarize out-of-tolerance data for a group of parts, to improve the data's readability, and to automatically create a product scorecard and/or a spreadsheet that summarizes the out-of-tolerance data. The program uses inspection data files generated by a CMM to create a Microsoft Excel spreadsheet which, in turn, creates a product scorecard spreadsheet and/or an inspection summary spreadsheet. The product scorecard contains a benchmark sigma value, along with averages, standard deviations, and yields for each measurement key. The inspection summary contains out-of-tolerance values and ranges for each measurement key, detailed for each serial number of the group of parts.

Several hardware and software improvements were provided for CMMs in the Precision Measurement department. Calibration, probe setup, and part fixturing hardware was purchased. Calypso software and upgrades were purchased for seven different Zeiss CMMs, and training for a Precision Measurement CMM inspector/programmer was purchased for Zeiss Calypso Curve, and Planner, and Simulation software.

Three different reverse engineering software packages were evaluated, and the Raindrop Geomagic Studio software was determined to have superior capabilities and an easy-to-use interface.

Funded by this project, KCP personnel contributed to and influenced the development of the Dimensional Measuring Interface Standard (DMIS), the Dimensional Markup Language (DML), 
and the Exchange of Quality Measurement Process Plan (eQuiPP) standard. These standards provide standardized file formats for CMM inspection programs and for measurement results.

Model-based engineering capabilities were expanded through the development of Feature-Based Tolerancing (FBTol) software for the tolerance analysis of piece parts and of Feature-Based Measuring (FBMeas) software for the creation of model-based CMM inspection programs and inspection plans and through the purchase and use of CETOL Six Sigma, off-the-shelf software for the tolerance analysis of mechanical assemblies.

To improve operational efficiency in the Precision Measurement department, a web-based application that allows tracking of CMM inspection jobs was created. The application interfaces with an Oracle database and allows departmental personnel to record information about inspection jobs, including time spent programming, time spent inspecting, inspection job type, receiving and shipping dates and locations, and equipment used.

\section{Discussion}

\section{Scope and Purpose}

The compression of weapons program schedules, the increased use of parts suppliers, and the increased emphasis on work-for-others projects has led to the need to increase efficiency and improve the capabilities of coordinate measuring machines (CMMs) at the Kansas City Plant (KCP). In addition, large amounts of inspection data must be analyzed before disposition can be made on parts submitted to the Precision Measurement department. Reverse engineering software had been purchased, but it had not been evaluated. Also, CMM standards that are necessary to enable CMMs to reach their full potential are not yet released for use in industry. Model-based methods that increase throughput and improve quality have not been fully implemented in KCP's CMM operations.

This project addressed these needs by performing work in several areas. CMM hardware and software needs were assessed, and equipment and software were purchased to meet those needs. Programs were created and enhanced to automate and improve the analysis of the high volume of CMM inspection data. Three different reverse engineering software packages were evaluated. Funded by this project, KCP personnel contributed to and influenced the development of the Dimensional Measuring Interface Standard (DMIS), the Dimensional Markup Language (DML), and the Exchange of Quality Measurement Process Plan (eQuiPP) standard. Model-based engineering capabilities were expanded through the development of Feature-Based Tolerancing (FBTol), a software package used for the tolerance analysis of piece parts, Feature-Based Measuring (FBMeas), another software package used for the creation of CMM inspection plans, and the purchase of CETOL, off-the-shelf software used for tolerance analysis of mechanical assemblies that works directly with Pro/ENGINEER. An obsolete database application used to track jobs in Precision Measurement was replaced by the Inspection Job Management System, a web-based application with improved query and reporting capabilities. 


\section{Prior Work}

ADAPT Project 706664, Advanced CMM Technology, performed work that was foundational for parts of this project. That project enabled the initial creation of the product scorecard and inspection summary programs, which were expanded and improved with this project. It also funded the purchase of three reverse engineering software packages, which were evaluated during this following project.

\section{Activity}

This project included several different activities, each of which addressed a technical gap in the areas of CMM technology and model-based technology.

\section{CMM Data Analysis}

Engineers and requesting inspection department personnel at the Kansas City Plant have been manually reviewing CMM inspection data for disposition of purchased and manufactured products. A program was developed to summarize out-of-tolerance data for a group of parts, to improve the data's readability, and to automatically create a product scorecard and/or a spreadsheet that summarizes the out-of-tolerance data. The program uses inspection data files generated by a CMM to create a Microsoft Excel spreadsheet which, in turn, creates a product scorecard spreadsheet and/or an inspection summary spreadsheet. The product scorecard contains a benchmark sigma value, along with averages, standard deviations, and yields for each measurement key. The inspection summary contains out-of-tolerance values and ranges for each measurement key, detailed for each serial number of the group of parts. See Figure 1 to view a pictorial representation of this process.

The program eliminates manual data entry, dramatically reduces the time to populate product scorecards, to review CMM inspection results, and to enter the data into reporting systems, and it improves the quality of the data. 


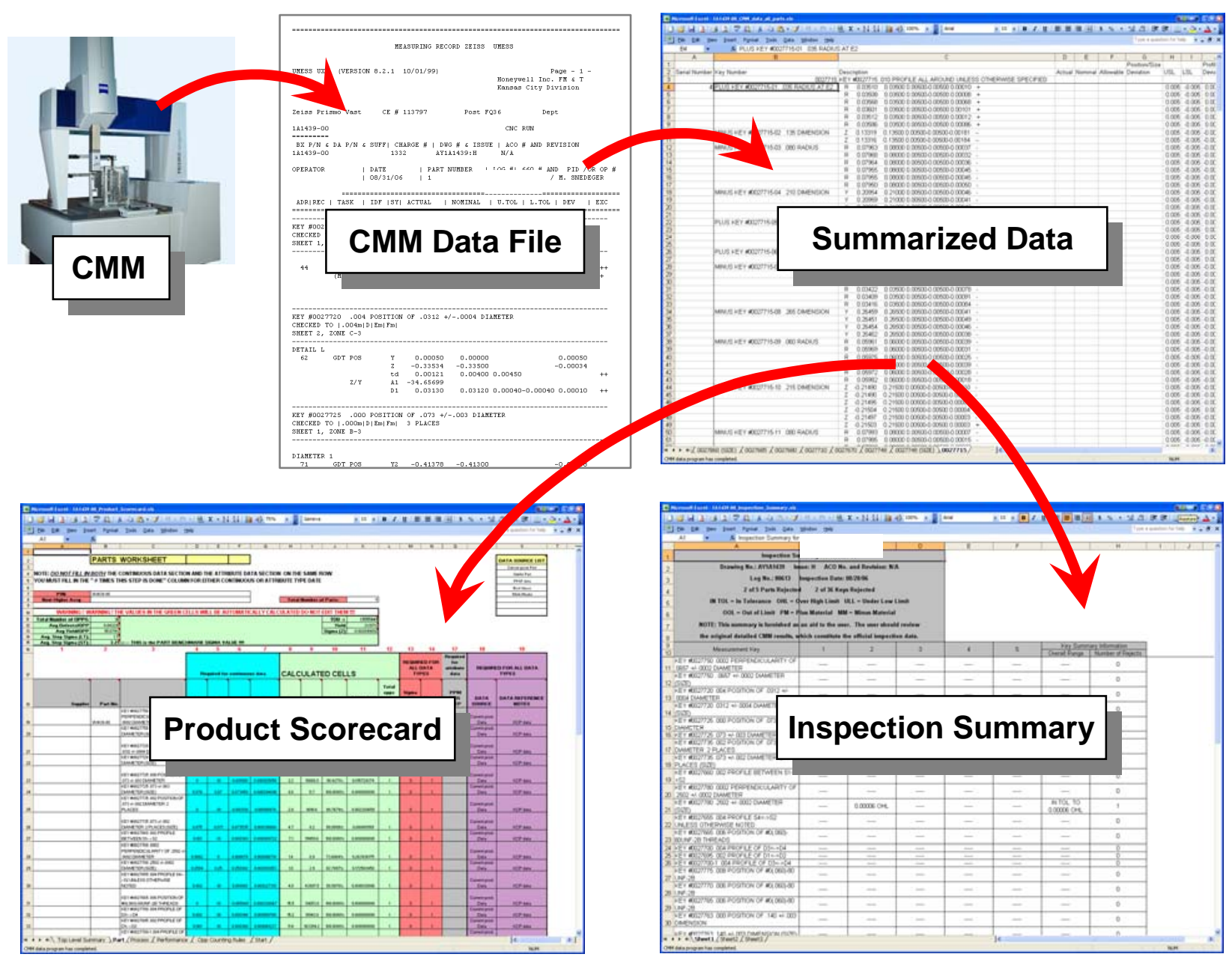

Figure 1: CMM Data Transfer Process 
The CMM product scorecard and inspection summary creation processes were improved such that the two manual processes that took hours were replaced with a single automated process that takes a few minutes.

The product scorecard (Figure 2) calculates average, standard deviation, and yield percentage values for each inspection key measured in a group of parts, and a benchmark sigma value is provided that serves as a quality metric to help determine the disposition of the parts.

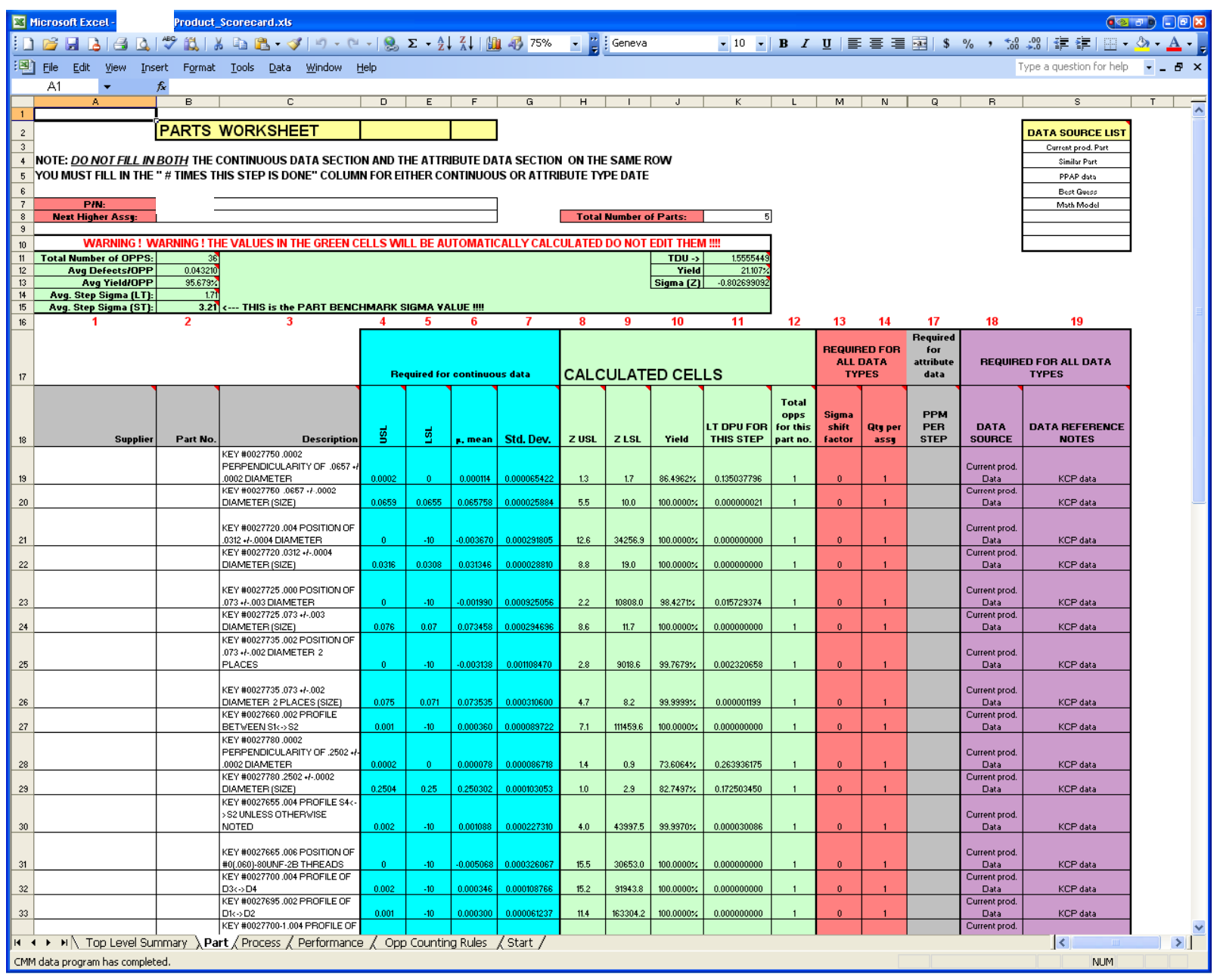

Figure 2: Product Scorecard 
The inspection summary (Figure 3) displays out-of-tolerance information for a group of parts in an easy-to-read, convenient manner for the engineer or requesting inspection department. Outof-tolerance values are listed, including high and low values if a range of measurements were made for an inspection key. The data is displayed in a matrix consisting of measurement keys in the rows and part serial numbers in the columns. The information is summarized for the entire group of parts, including the number of keys rejected for a particular serial number, the overall range of out-of-tolerance values and the number of rejects for a particular measurement key, the number of parts rejected, and the number of keys rejected.

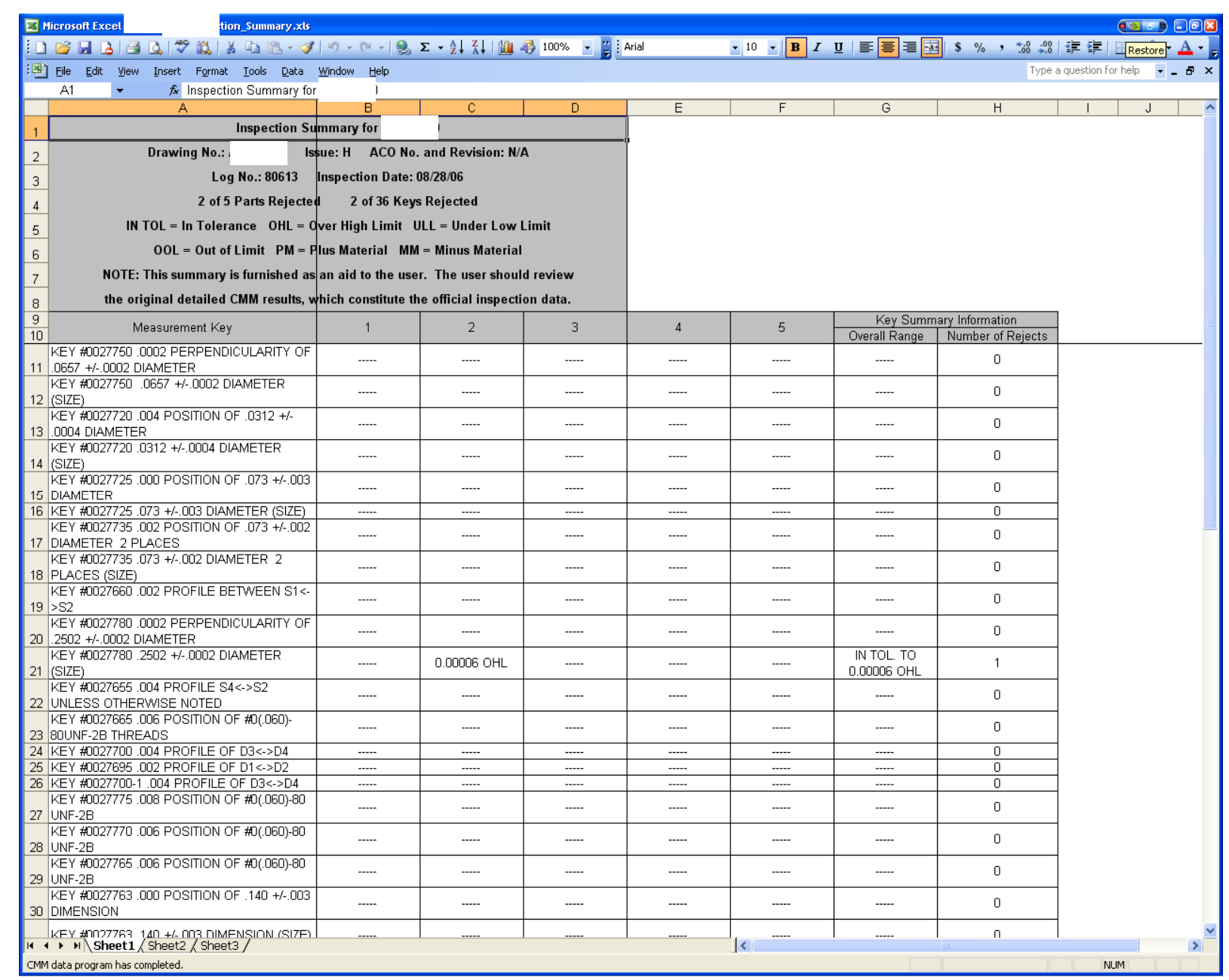

Figure 3: Inspection Summary

Work funded by this project expanded the capabilities of this program so that inspection data files generated by Zeiss CMMs running either UMESS or UMESS-LX software, Apollo CMMs running either MeasureMax or Metrologic software, and the OGP measuring machine can be used to create product scorecards and inspection summaries. See Figures 4 through 8. 


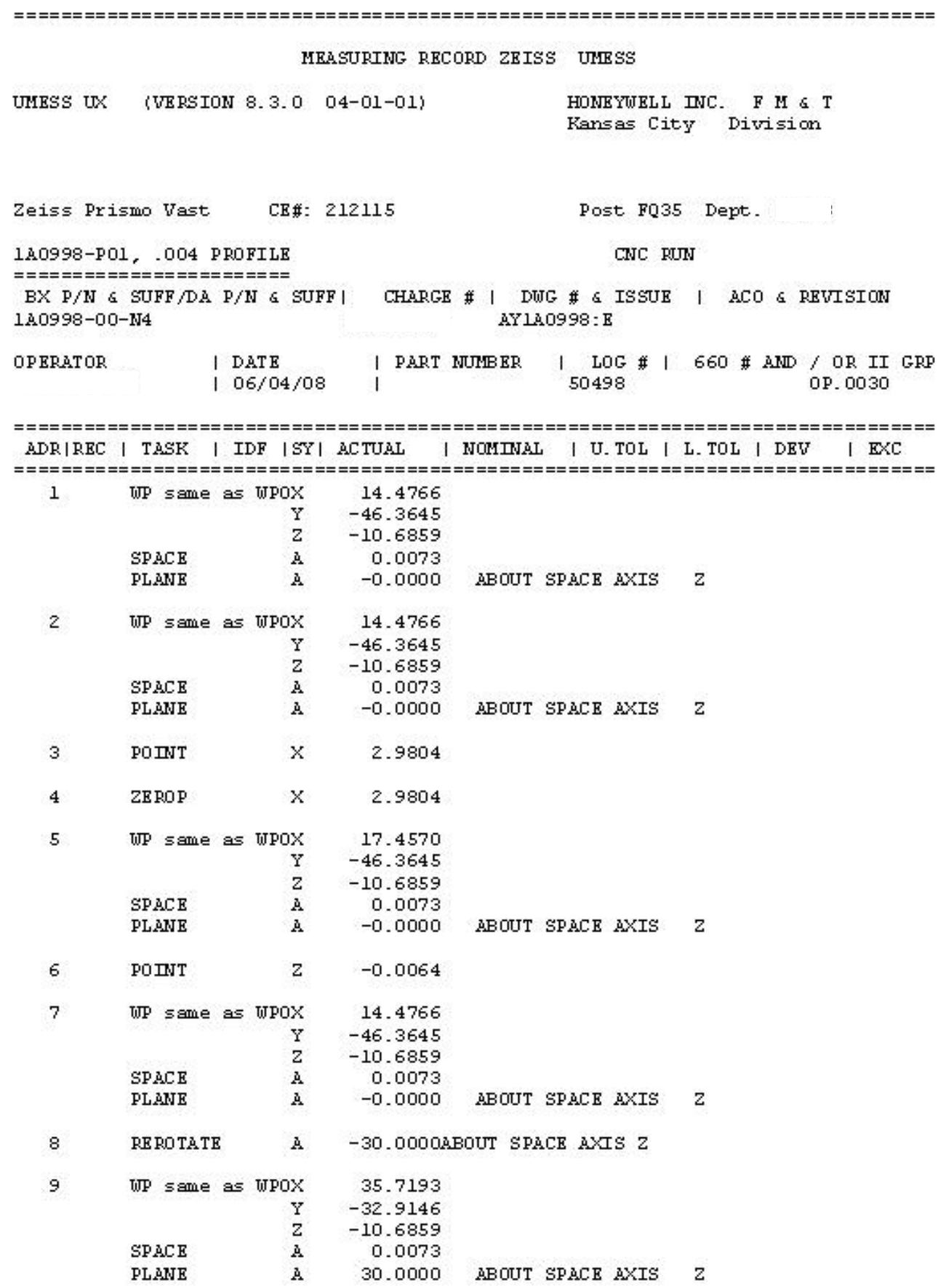

Figure 4: Zeiss UMESS Data File (Page One of Many) 


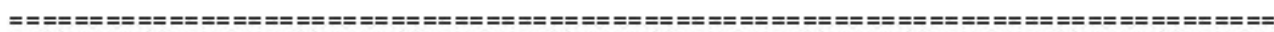

MEASURING RECORD ZEISS UMESS

UMESS-LX (VERSION 1.6.0/ DEC, 2002)

HONEYTELL FMGT

KANSAS CITY PLANT

ZEISS PRISMO 7 S-ACC VAST

CE\# 211754

POST FL34 DEPT.

CM423756-000:B

CNC RIN

$=============$

$\mathrm{BX} \mathrm{P} / \mathrm{N} \& \mathrm{SUFF} / \mathrm{DA} / \mathrm{P} / \mathrm{N} \&$ SUFF CHARGE \# I DUG \# \& ISSUE I ACO $\&$ REVISION I 423756: C

OPERATOR I DATE I PART NTMRER I LOG I 660 AMD/OR II GROUP

$$
\text { I } 11 / 14 / 07 \quad 110343 \quad 1173 \quad \text { OPER. }
$$

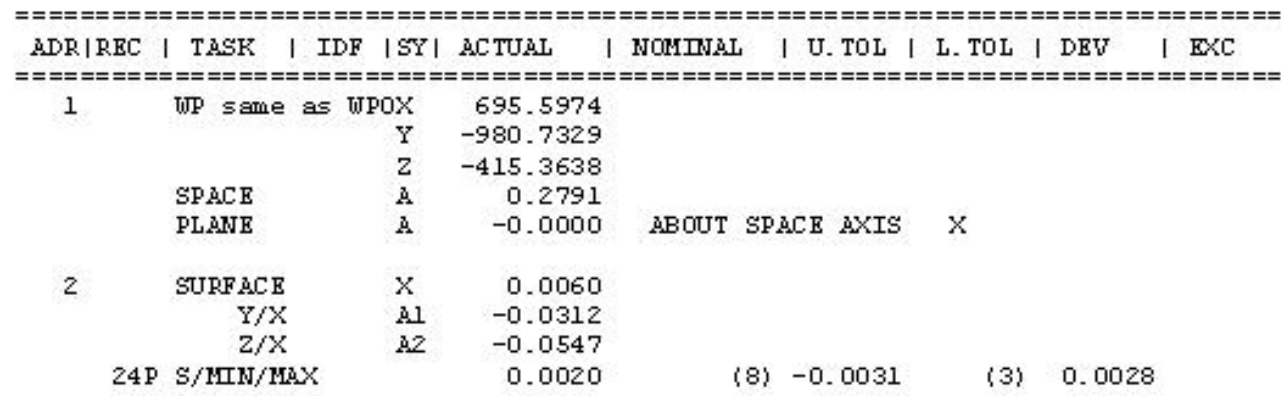

KEY $\$ 0090009$

|0.1|FLATNESS| OF - A-

REQUIREMENT \#9

LOCATION $1 \mathrm{CS}$

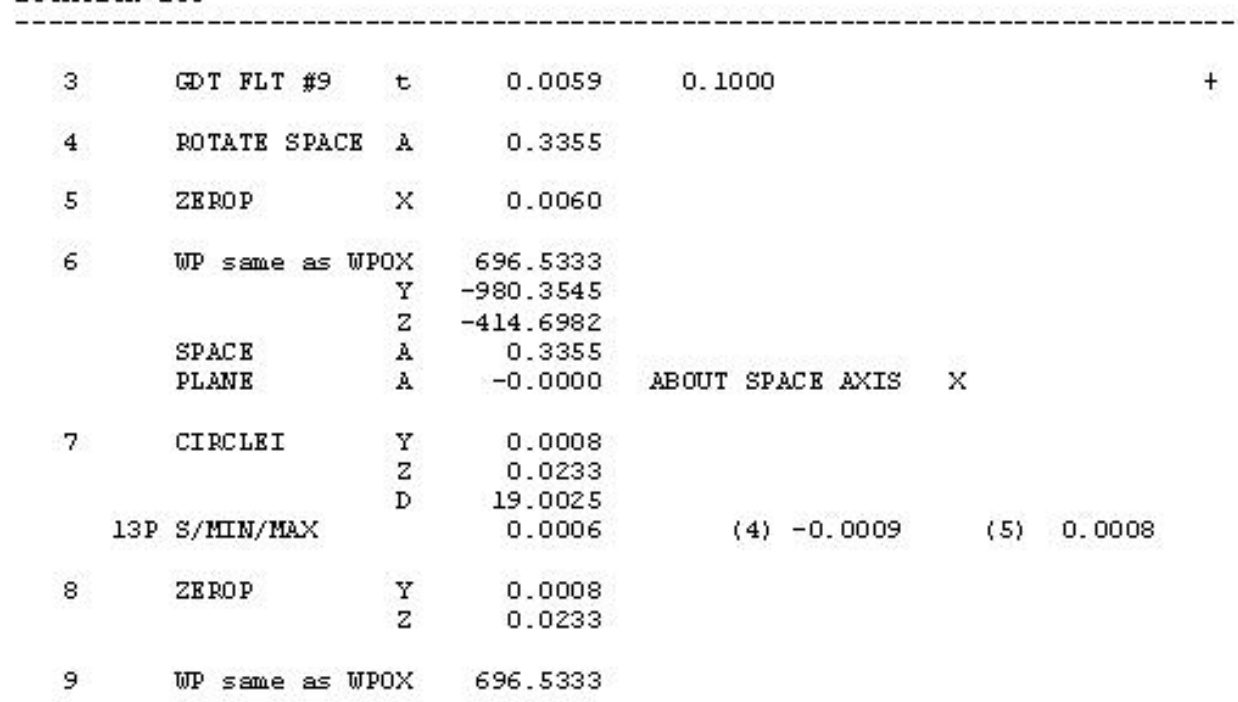

Figure 5: Zeiss UMESS-LX Data File (Page One of Many) 


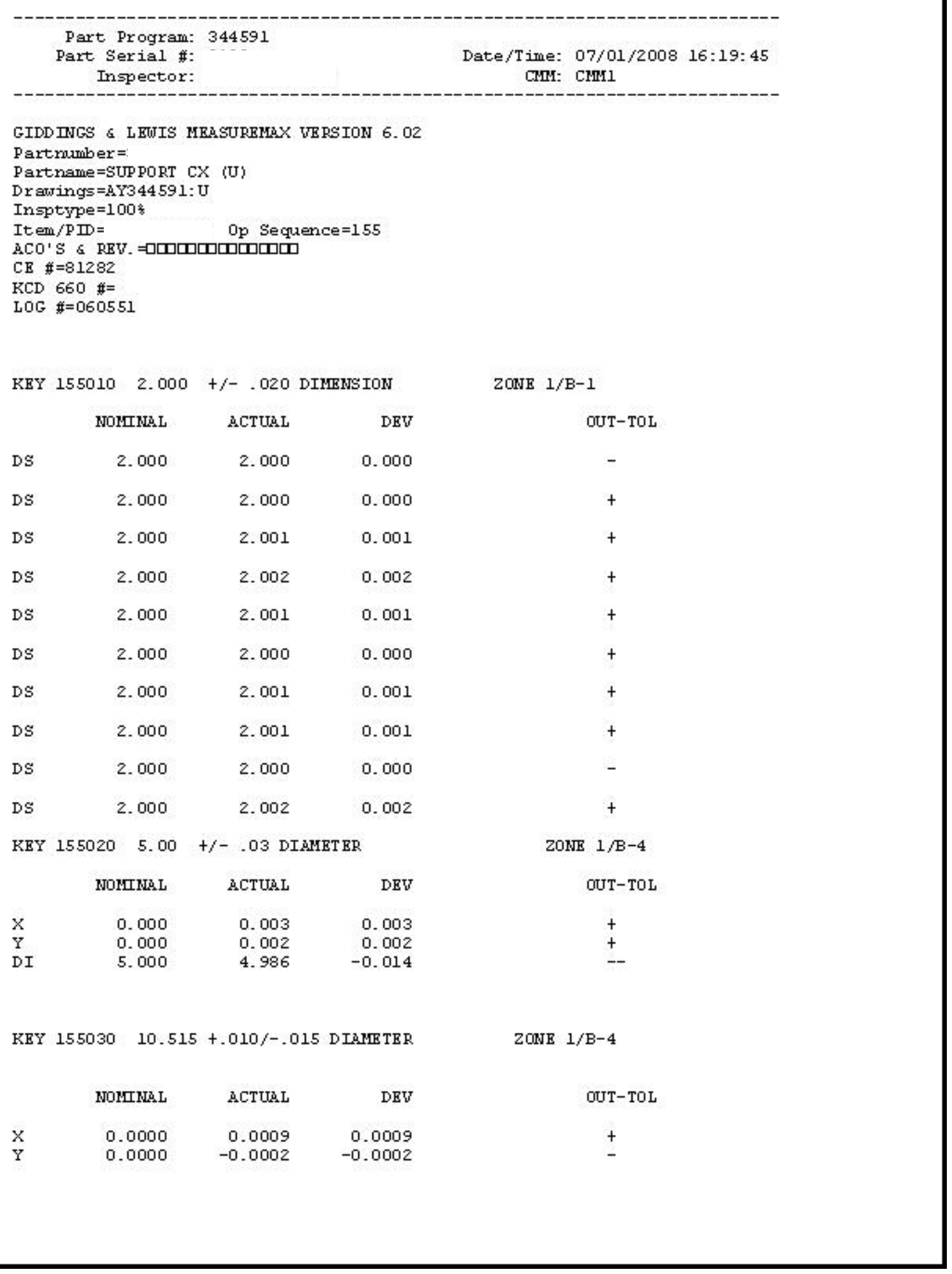

Figure 6: Apollo MeasureMax Data File (Page One of Many) 


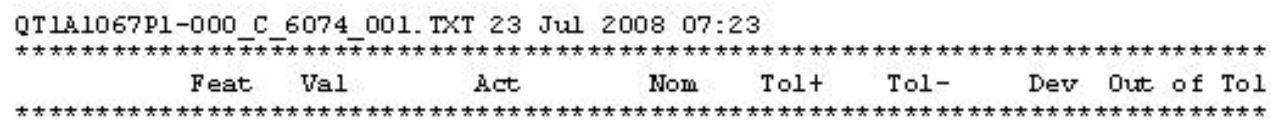

Part Program:

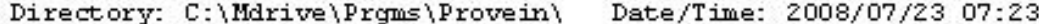

Inspector:

CMIM: CE_82951

Part Serial \#:

LOG NUMBER : 2008070361

PII NUMBER :

PART NUMBER:

PART SUFFIX: 00

PART NuME : Housing, Full Machined

CLASSIFICAT ION: UNCLÁSSIFIED

DRAIING/ISS: AYLL1067 Iss $\mathrm{K}$

ML/ISSUE : $1 \mathrm{Al} 067 \mathrm{Iss} \mathrm{J}$

ACO NUMEER: N/A

WORK TYPE : PRODUCTION

EXECUTIUE SOFTWARE : MetrologXG v8.00

NOTES:

Letter (s) at end of Part Program No. = Issue of Part Program

Is aues of DRHJTHG and ML = Issues when Part Program was released

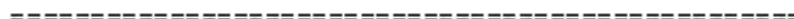

PM PARTNO:

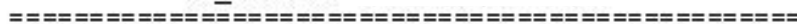

GROUP/KEY NUMBER $=503$

\begin{tabular}{|c|c|c|c|c|c|c|}
\hline \multicolumn{7}{|c|}{ 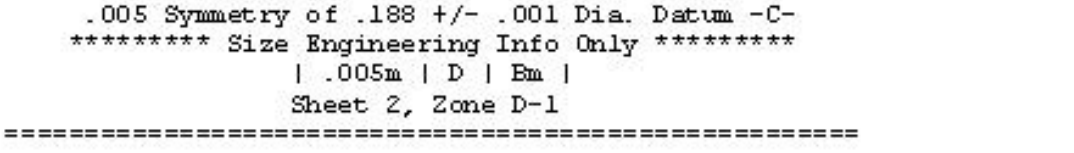 } \\
\hline CIRC $2 \mathrm{~A}$ & $\mathrm{x}$ & -0.0000 & 0.0000 & 9.0000 & -9.0000 & -0.0000 \\
\hline CIRCZA & DIMM & 0.1880 & 0.1880 & 0.0010 & -0.0010 & -0.0000 \\
\hline TOL3001 & PTOL & 0.0001 & 0.0000 & 0.0060 & & 0.0001 \\
\hline CIRC $25 \mathrm{~A}$ & $\mathrm{x}$ & 0.0000 & 0.0000 & 9.0000 & -9.0000 & 0.0000 \\
\hline CIRC $25 \mathrm{~A}$ & D IMM & 0.1880 & 0.1880 & 0.0010 & -0.0010 & -0.0000 \\
\hline TOL3003 & PTOL & 0.0001 & 0.0000 & 0.0060 & & 0.0001 \\
\hline
\end{tabular}

GROUP $/$ KEY NUMB ER $=101$

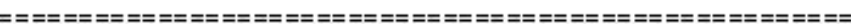

$4.797+/-.003$ Dia. Datum $-\mathrm{B}-$

Figure 7: Apollo Metrologic Data File (Page One of Many) 
Page: 1

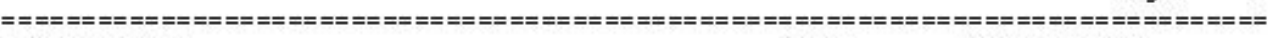
Routine Name Rum \# Date $s$ Time

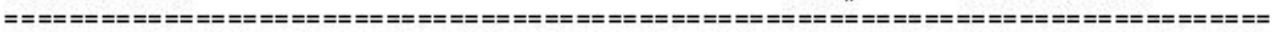
st 257804-000-e, rth $\quad$ 1 Thu Jul 06 09:13:26 2006

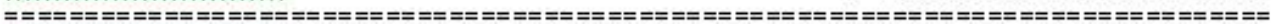
CE 211741

P/N: FLEX CIRCUIT LONG (U)

INSPECTED PER: DRUTE

INSPECTED BY:

OGP LOG\# 3878

SAMPLE\# 8147

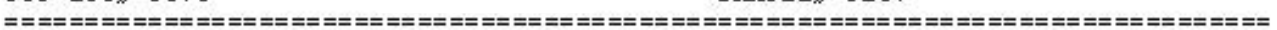

Feature Unit Nominal Actual Tolerances Deviation Exceeded

Step 49 - PART INSPECTED WITH DATUM -A- DOTR \& PART\# FACDNG UP

$\begin{array}{llll}\text { Result } \quad+000.0000+000.0000 & +000.0000\end{array}$

Step 50 - KRYO0l 0.100 PROF|A|SITI3X

Result im to00.0000 +000.0000

$+000.0000$

Step 51 - KEYOOL-0LA 0.25 DIM (TOP EDGE PADl) +DEV=+MAT'L

Profile + min $\quad+000.0071+00.0250$

$+000.0071++$

profile -

Step 52 - KRYO01-0ZA 0.25 FULL RAD (PADl) +DEV=+MAT'L

Profile $t$ mm $\quad+000.0000+00.0250 \quad+000.0000$

Profile - $\quad$ min $\quad-000.0308 \quad-00.0750 \quad-000.0308$

Step 53 - KEYO01-03A -0.25 DTM (BOTTOM EDGE PADl) +DEV=+MAT'L

Profile $+\quad+\quad+000.0029+00.0250 \quad+000.0029+$

Profile - min $\quad-000.0039 \quad-00.0750-000.0039$

Step 55 - KRYO01-04A 0.25 RAD(BOTTOM CORNER PADL) +DEV=+MAT'L

$\mathrm{R}$ Location $\mathrm{mm}+000.2500+000.2405+00.0250-00.0750 \quad-000.0095$

Step 56 - KEYO01-05A $0.25 \mathrm{RAD}$ (TOP CORNER PADL) +DEV=+MAT'L

R Location min $+000.2500+000.2399+00.0250-00.0750-000.0101$

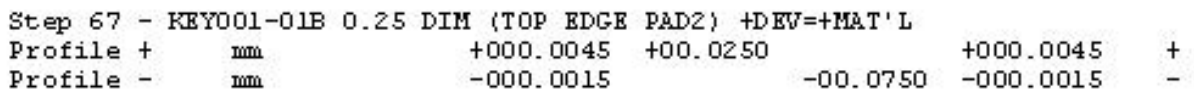

$\begin{array}{ccc}\text { Step } 68 \text { - KEYO01-0ZB } 0.25 \text { FULL RAD (PAD2) +DEV =+MAT'L } & \\ \text { Profile } t & +000.0000+00.0250 & +000.0000\end{array}$

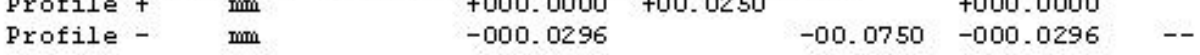

Step 69 - KEYOOL-03B -0.25 DTM (BOTTOM EDGE PAD2) +DEV=+MAT'L

Profile $t+\mathrm{mm} \quad+000.0162+00.0250 \quad+000.0162 \quad+++$

profile - min $\quad+000.0000 \quad-00.0750+000.0000$

Step 71 - KEYO01-04B 0.25 RAD (BOTTOM CORNER PAD2) +DEV=+MAT'L

$R$ Location mi t000.2500 +000.2387 +00.0250 -00.0750 -000.0113 -

Step 72 - KRYO01-05B $0.25 \mathrm{RAD}$ (TOP CORNER PADZ) +DEV=+MAT'L

R Location min t000.2500 +000.2331 +00.0250 $-00.0750-000.0169 \quad-$

Step 90 - KEYO01-01C 0.25 DIM (TOP EDGE PAD3) +DEV=+MAT'L

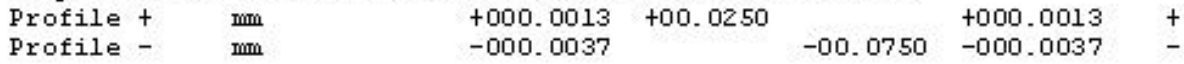

Figure 8: OGP Data File (Page One of Many) 


\section{CMM Hardware and Software Improvements}

\section{Hardware Improvements}

Hardware purchases totaling $\$ 17 \mathrm{~K}$ were made with funds from this project. A calibration sphere was purchased for the OGP measuring machine, and a vacuum pump was purchased to assist in the fixturing of foam parts for inspection. In addition, a probe setup aid was purchased for use on any of several Zeiss CMMs, and a set of probe adapter plates was purchased for the Zeiss

\section{CARAT CMM.}

\section{Software Improvements}

Project funds totaling $\$ 32 \mathrm{~K}$ were used to purchase software in support of KCP's CMM operation. Calypso software (Figure 9) and upgrades were purchased for seven different Zeiss CMMs. Training for a Precision Measurement CMM inspector/programmer was purchased for Zeiss Calypso Curve, and Planner, and Simulation software.

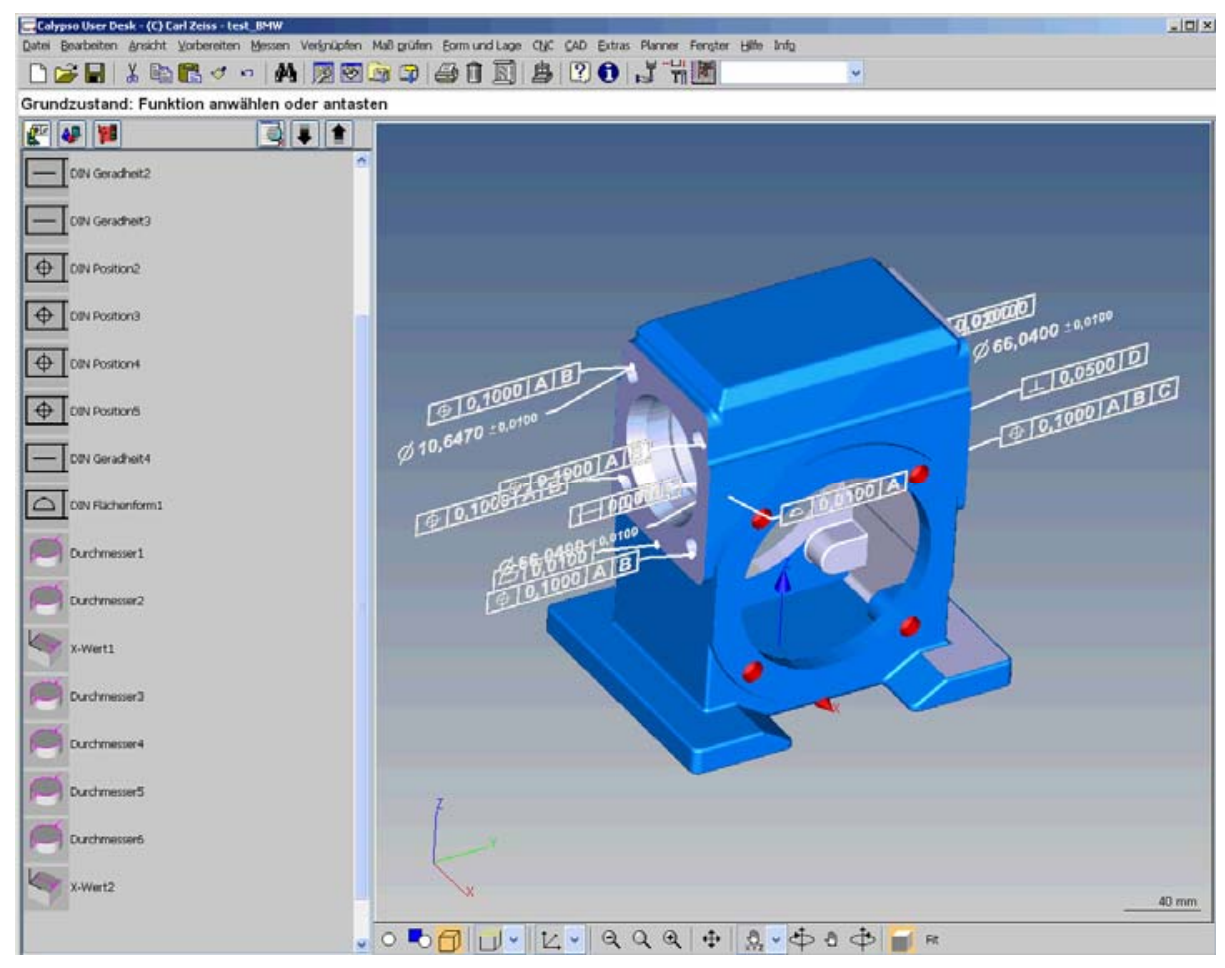

Figure 9: Zeiss Calypso Software

The Calypso Planner software (Figure 10) enables off-line programming of Zeiss CMMs using solid models. Solid models of the Zeiss CMM, fixtures, and probe setups are used with a solid model of one of KCP's parts, and an inspection program can be created in a user-friendly and intuitive virtual environment. 


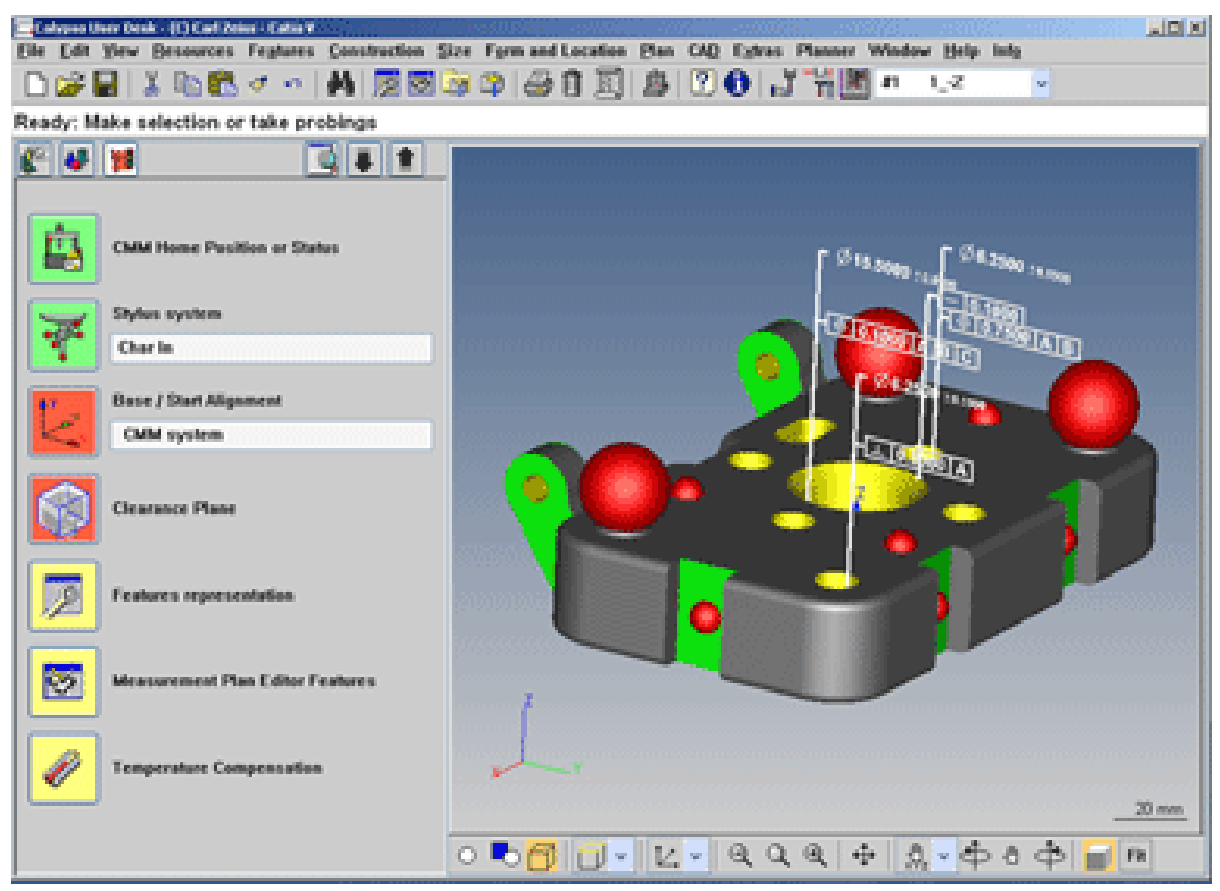

Figure 10: Zeiss Calypso Planner Software

The Calypso Simulation software (Figure 9) allows the programmer to test an inspection program in the virtual environment, so that errors are kept to a minimum and the program can be optimized. These methods reduce the time required to create part inspection programs, and they free up CMMs to measure more parts. 


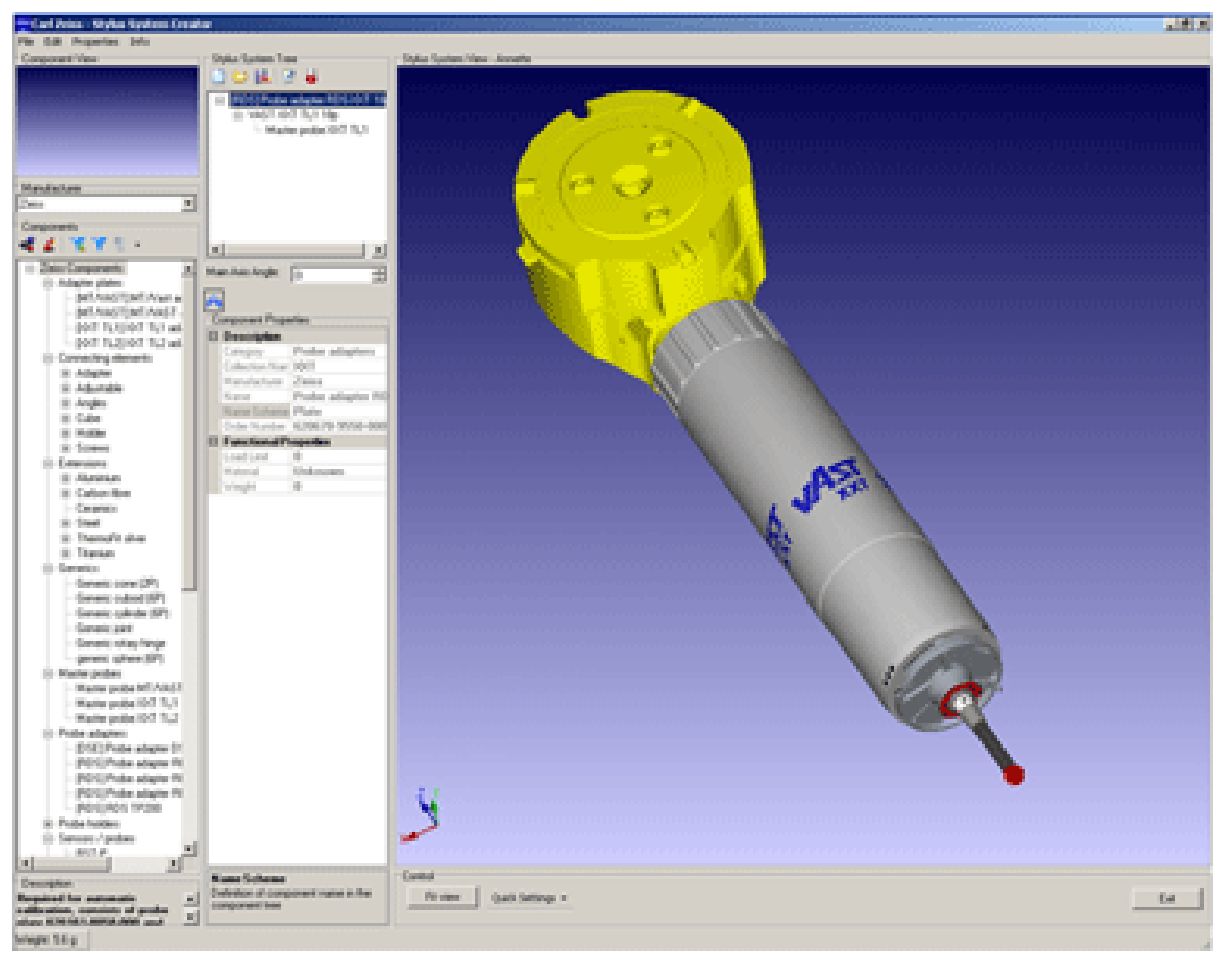

Figure 11: Zeiss Calypso Simulation Software

\section{$\underline{\text { Reverse Engineering Software Evaluation }}$}

Three different reverse engineering software packages were evaluated. The Raindrop Geomagic Studio software package (Figure 12) was determined to have superior capabilities and an easyto-use interface. $\$ 13 \mathrm{~K}$ was allocated for labor expended in this evaluation. 


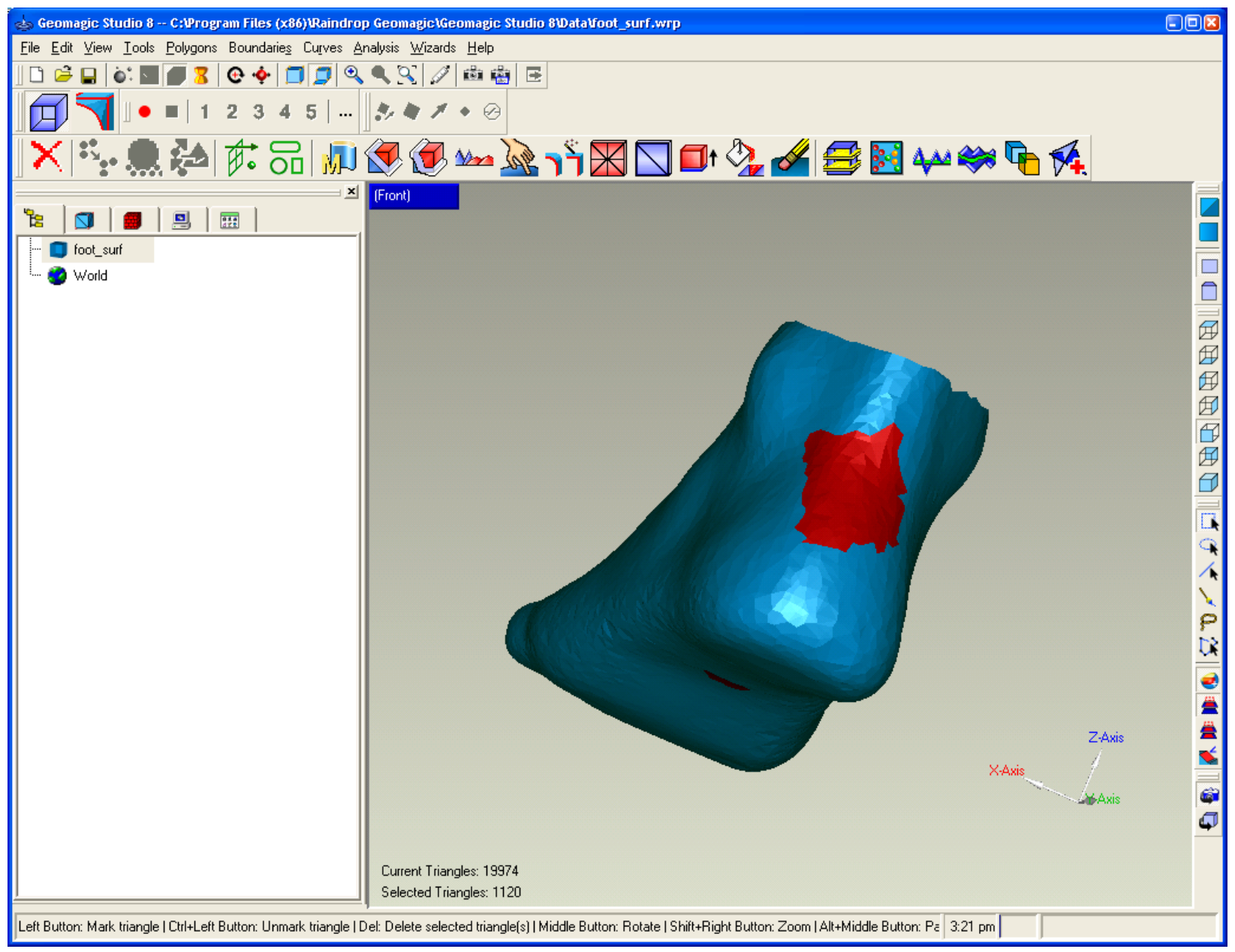

Figure 12: Raindrop Geomagic Studio Reverse Engineering Software 


\section{Dimensional Metrology Standards}

Funded by this project, KCP personnel contributed to and influenced the development of the Dimensional Measuring Interface Standard (DMIS), the Dimensional Markup Language (DML), and the Exchange of Quality Measurement Process Plan (eQuiPP) standard. DMIS (Figure 13) is a standard file format used to run coordinate measuring machines and to translate inspection programs from one data format to another. DML is an emerging standard that provides a common method for storing measurement results. This project funded $\$ 81 \mathrm{~K}$ for labor, $\$ 12 \mathrm{~K}$ for materials, and $\$ 12 \mathrm{~K}$ for travel in support of this standards work.

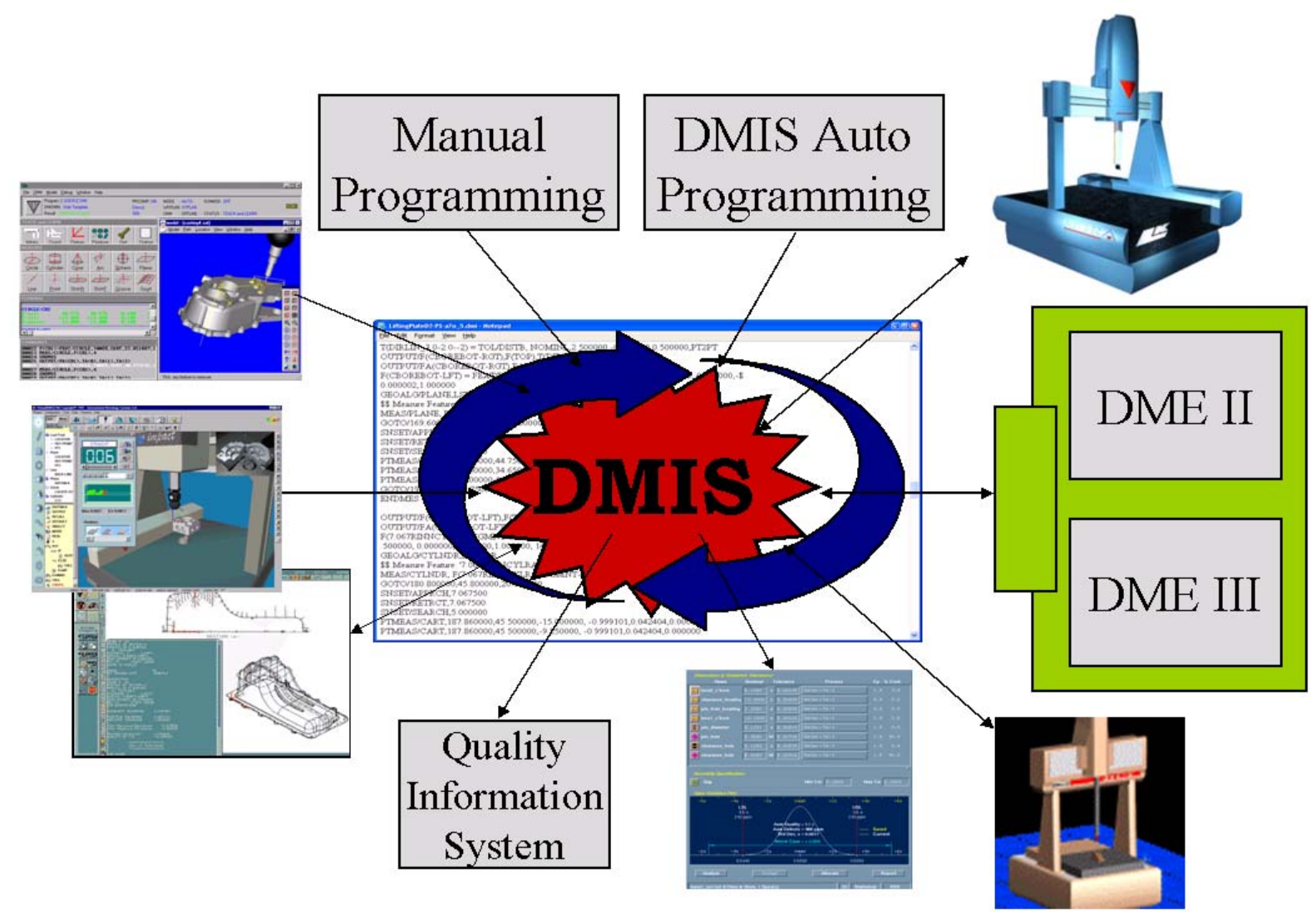

Figure 13: Dimensional Measuring Interface Standard (DMIS) 


\section{Model-Based Enterprise}

This project funded work for the development of Feature-Based Tolerancing (FBTol), modelbased software that analyzes piece parts for complete and unambiguous tolerance schemes (Figure 14), and Feature-Based Measuring (FBMeas), which generated CMM inspection programs and helps create intelligent inspection plans.

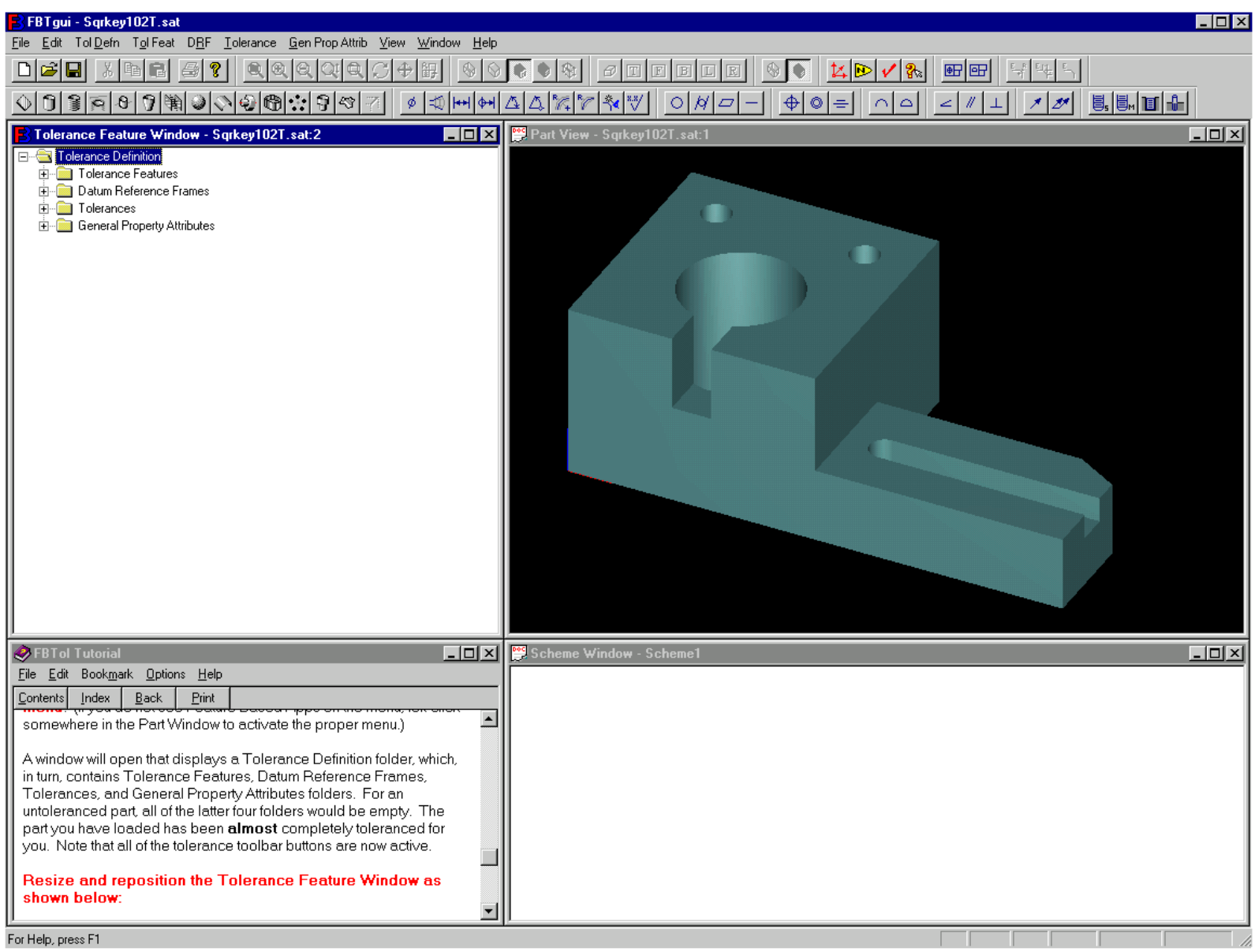

Figure 14: Feature-Based Tolerancing (FBTol) 
Off-the-shelf software, CETOL Six Sigma (Figure 15), was purchased and used for the tolerance stackup analysis of mechanical assemblies. The tool allows the user to define suspected trouble areas in an assembly and use sophisticated algorithms to determine if potential interference conditions exist, and if those conditions do exist, it identifies methods to eliminate the problems. The product works concurrently with Pro/ENGINEER.

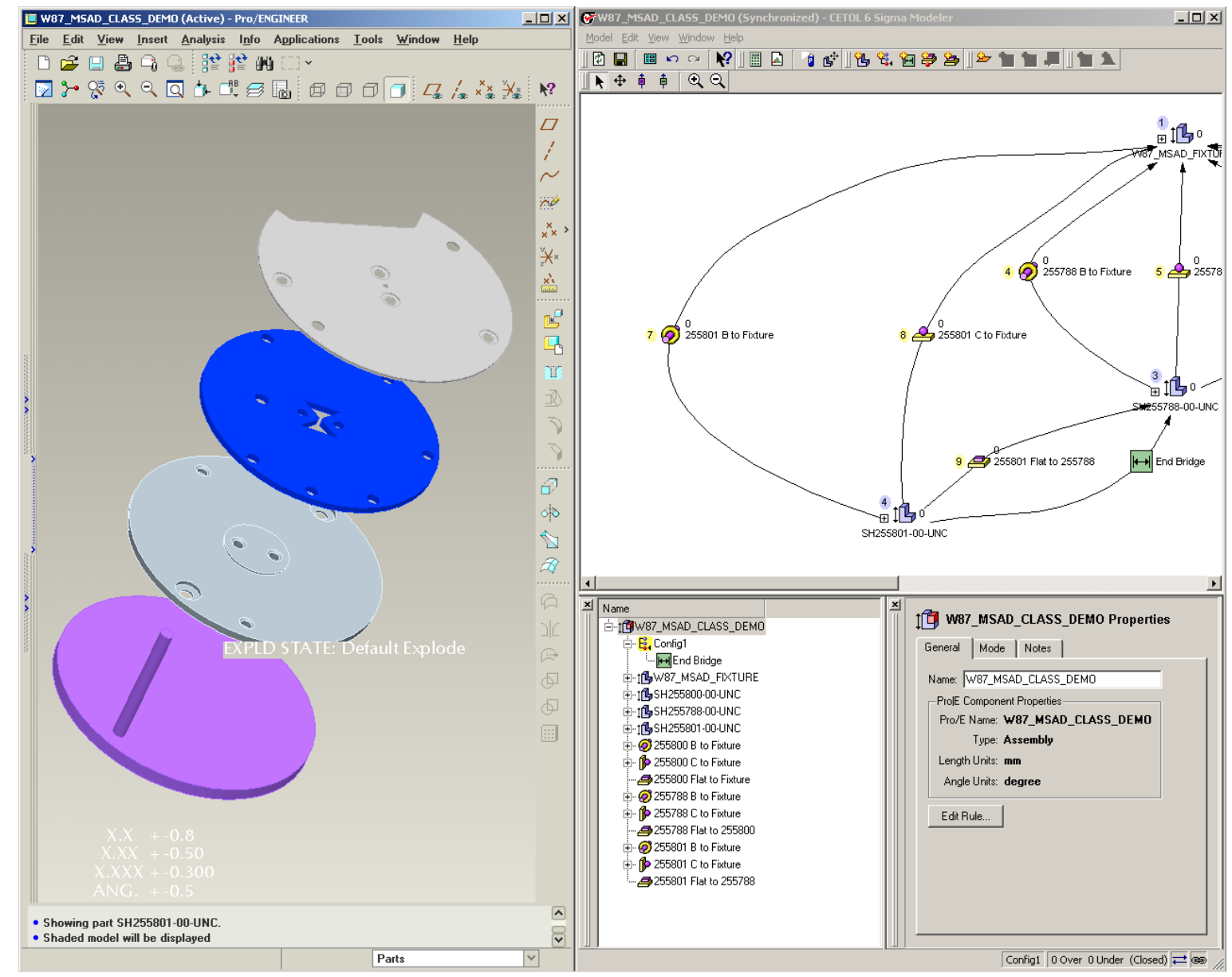

Figure 15: CETOL Six Sigma 


\section{Precision Measurement Database}

A web-based application that allows tracking of CMM inspection jobs in the Precision Measurement department was created. The application interfaces with an Oracle database and allows department personnel to record information about inspection jobs, including time spent programming, time spent inspecting, inspection job type, receiving and shipping dates and locations, and equipment used. Figure 16 shows the system's main menu.

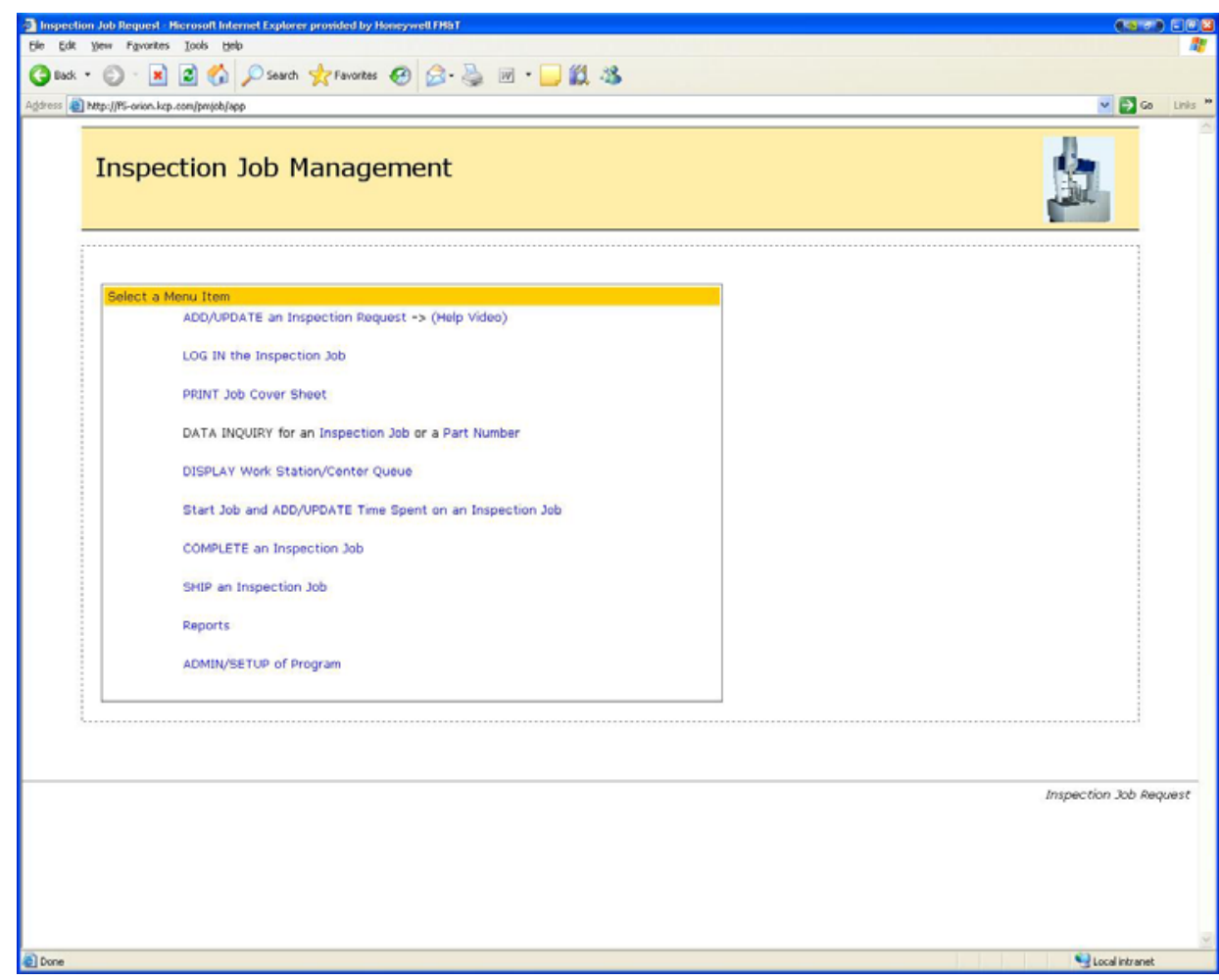

Figure 16: Job Management System: Main Menu

The new application includes customized reports and charts that allow the user to view such things as cycle time (Figures 17 and 18) and average monthly estimated and actual inspection time (Figure 19). This system allows inspectors and the department manager to more efficiently manage their inspection work and to provide more accurate and timely information to their customers. This project provided $\$ 231 \mathrm{~K}$ in funding for the labor required to develop, deploy, and maintain this application. 


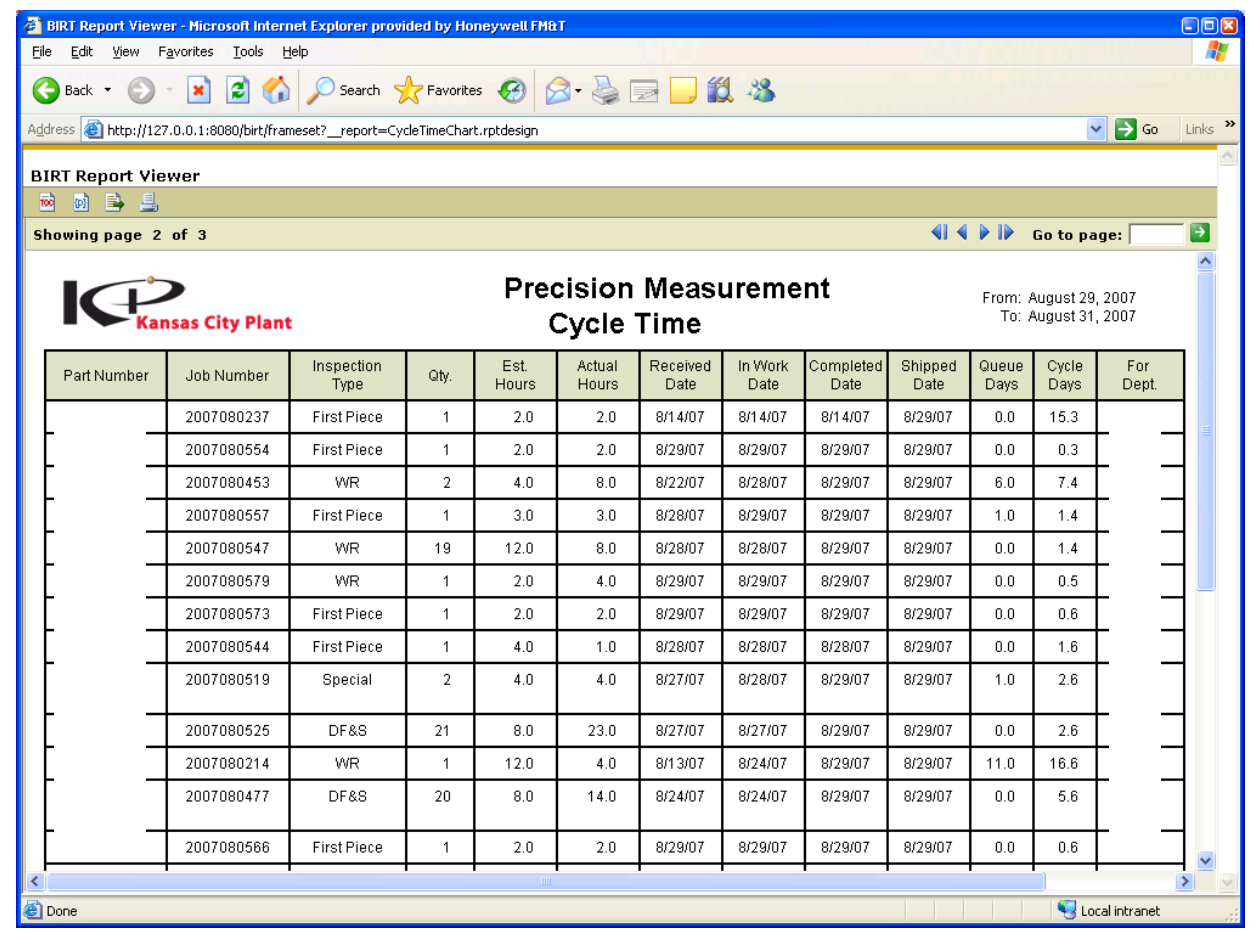

Figure 17: Job Management System: Cycle Time Table

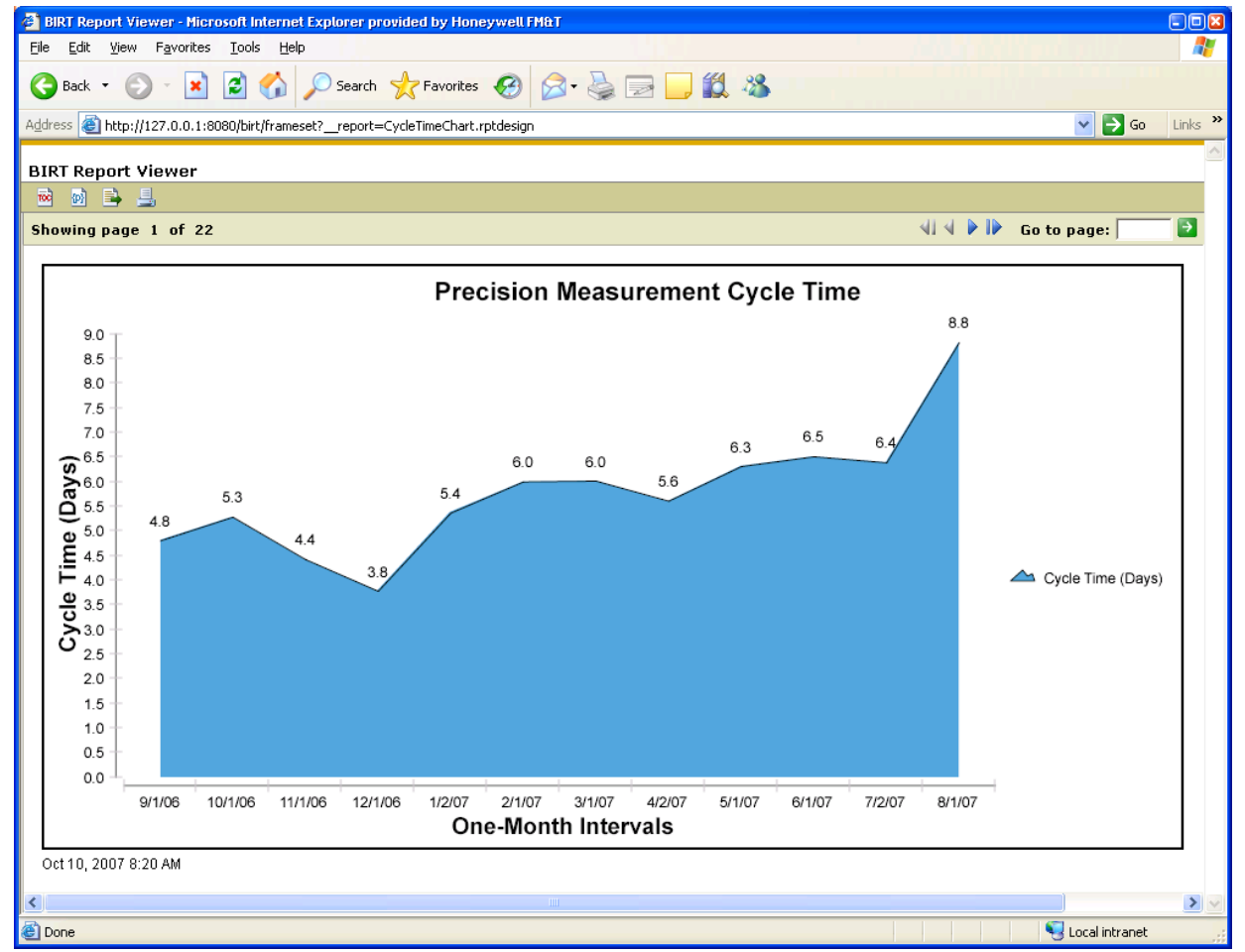

Figure 18: Job Management System: Cycle Time Chart 


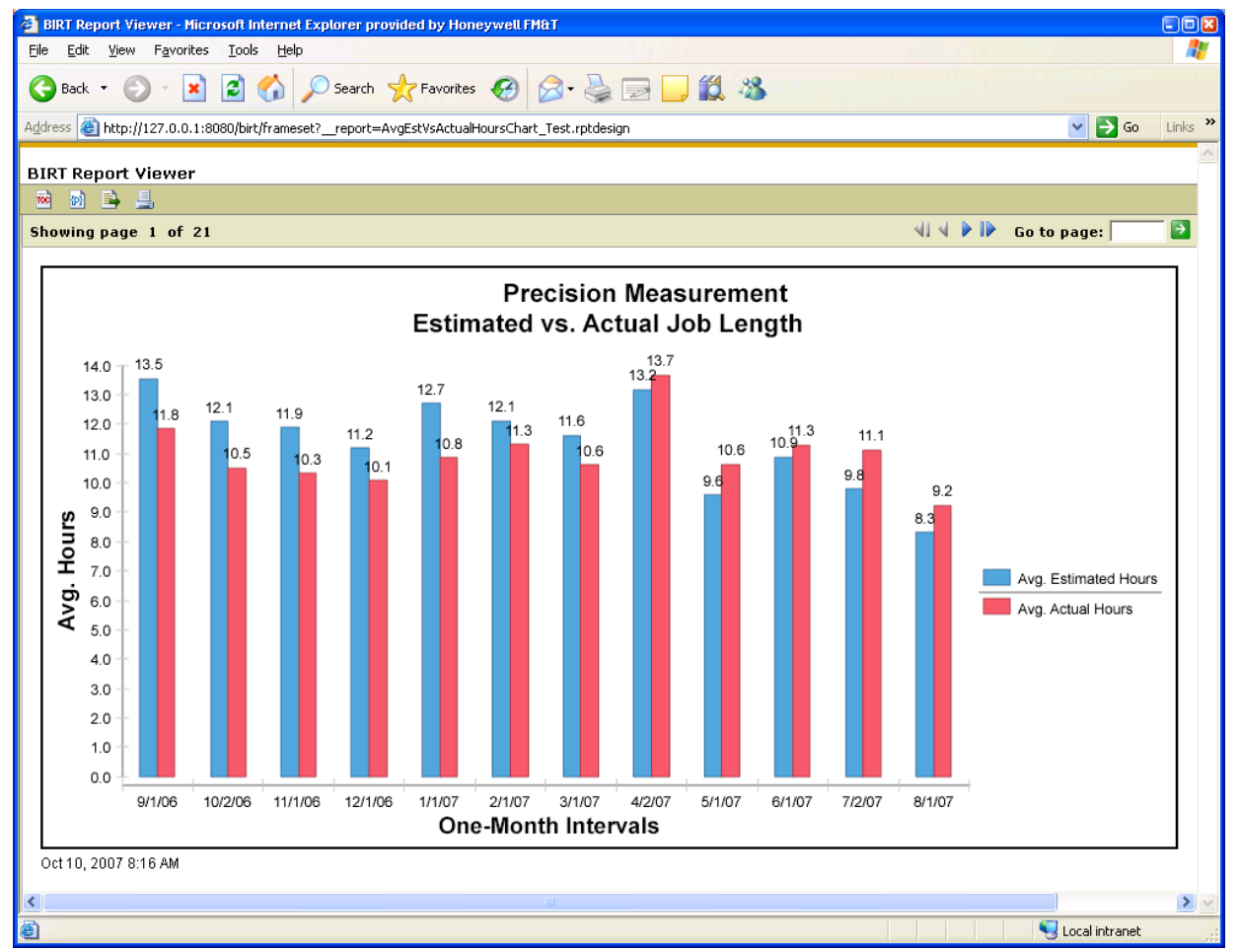

Figure 19: Job Management System: Estimated Vs. Actual Time

\section{Accomplishments}

CMM hardware and software needs were assessed, and equipment and software were purchased to meet those needs. Programs were created and enhanced to automate and improve the analysis of the high volume of CMM inspection data. Three different reverse engineering software packages were evaluated. Funded by this project, KCP personnel contributed to and influenced the development of the Dimensional Measuring Interface Standard (DMIS), the Dimensional Markup Language (DML), and the Exchange of Quality Measurement Process Plan (eQuiPP) standard. Model-based engineering capabilities were expanded through the development of Feature-Based Tolerancing (FBTol), a software package used for the tolerance analysis of piece parts, Feature-Based Measuring (FBMeas), another software package used for the creation of CMM inspection plans, and the purchase of CETOL, off-the-shelf software used for tolerance analysis of mechanical assemblies that works directly with Pro/ENGINEER. An obsolete database application used to track jobs in Precision Measurement was replaced by the Inspection Job Management System, a web-based application with improved query and reporting capabilities. 


\section{Future Work}

Work remains to be done in several areas of CMM and model-based technology. The generation of product scorecards and inspection summaries should be fully automated such that it happens in the background, with no intervention from the inspectors running the CMMs. The inspection data files should be placed in a public folder that can be accessed by engineers and other inspection departments as needed. Inspection data from all of the various makes of CMMs should be standardized, and this standardization should ultimately be in the format of the Dimensional Markup Language. The CMMs in the Precision Measurement department are not yet networked in either the classified or unclassified environments. When this is accomplished, common network directories should be created in these environments for the storage of CMM inspection programs and inspection results files. Data analysis capabilities should also be extended to KCP suppliers with their own CMMs. KCP's influence and involvement with the various CMM-related standards should be continued. The Inspection Job Management System will be discontinued with the rollout of Solumina, the replacement for the current MES system, and work will be required to migrate the old system's capabilities and legacy data into the new system. Work needs to be initiated to transform KCP's dimensional metrology enterprise to an efficient, seamless system where product design information, CMM inspection programs, inspection data, and results analysis are available from an engineer's desktop. 